\title{
IGF-II promoter specific methylation and expression in epithelial ovarian cancer and their associations with disease characteristics
}

\author{
BIYUN QIAN ${ }^{1,2}$, DIONYSSIOS KATSAROS ${ }^{3}$, LINGENG LU ${ }^{1}$, EMILIE MARION CANUTO ${ }^{3}$, \\ CHIARA BENEDETTO ${ }^{3}$, ALICIA BEEGHLY-FADIEL ${ }^{4}$ and HERBERT YU ${ }^{1}$
}

\begin{abstract}
${ }^{1}$ Department of Epidemiology and Public Health, Yale Cancer Center, Yale University School of Medicine, New Haven, CT 06520-8034, USA; ${ }^{2}$ Department of Epidemiology, Tianjin Medical University Cancer Institute and Hospital, Key Laboratory of Cancer Prevention and Therapy, Tianjin, P.R. China; ${ }^{3}$ Department of Obstetrics and Gynecology, Gynecologic Oncology and Breast Cancer Unit, University of Turin, Turin, Italy; ${ }^{4}$ Division of Epidemiology, Department of Medicine, Vanderbilt Epidemiology Center, Vanderbilt University School of Medicine, Nashville, TN, USA
\end{abstract}

Received July 8, 2010; Accepted August 13, 2010

DOI: 10.3892/or_00001062

\begin{abstract}
High expression of insulin-like growth factor-II (IGF-II) in epithelial ovarian cancer is associated with aggressive disease and poor prognosis. IGF-II transcription is initiated from multiple promoters. Promoter-specific expression is regulated by DNA methylation, which is often dysregulated in cancer. Here, the effects of promoter-specific methylation on IGF-II expression are investigated in ovarian cancer. Fresh tumor samples were collected from 211 patients for analyses of IGF-II promoter methylation using methylationspecific PCR, and of promoter-specific expression of IGF-II mRNA with qRT-PCR, as well as tissue levels of IGF-II peptide with an ELISA. Cox regression analysis was performed to assess IGF-II methylation and expression in association with progression-free and overall survival. DNA methylation was high in IGF-II promoters $2(\mathrm{P} 2,64.2 \%)$ and $3(\mathrm{P} 3,52.1 \%)$ and low in promoter $4(\mathrm{P} 4,9.8 \%)$. High methylation was associated with low mRNA expression in a promoter-specific manner. P3 methylation and expression appeared to be critical in ovarian cancer compared to other promoters. While methylation in an individual promoter was not associated with the disease, a methylation pattern involving P2 and P3 was significantly different among patients with distinct tumor grade, debulking results, residual tumor size and treatment response. The methylation pattern was also associated with disease progression. The study suggests that DNA methylation regulates IGF-II promoter-specific expression in ovarian cancer and the regulation may play a
\end{abstract}

Correspondence to: Dr Herbert Yu, Department of Epidemiology and Public Health, Yale Cancer Center, Yale University School of Medicine, 60 College Street, New Haven, CT 06520-8034, USA E-mail: herbert.yu@yale.edu

Key words: IGF-II, methylation, epithelial ovarian cancer, prognosis role in disease progression. Assessing methylation patterns in IGF-II promoters may have clinical implications.

\section{Introduction}

Epithelial ovarian cancer is one of the most lethal malignancies. Less than half of the patients attracting the disease survive over 5 years. Due to the lack of symptoms and clinical signs, most patients are diagnosed at a late stage of the disease to which few effective therapies are available. Early detection and effective treatment remain to be a challenge. Further molecular characterization of ovarian cancer will help not only to improve our understanding, but also provide new alternatives for early detection and better management of the disease.

Insulin-like growth factors (IGFs), including IGF-I and IGF-II, are important peptides which regulate essential cellular activities (1). Dysregulation of IGF actions is linked to a number of human diseases including cancer (2). Although IGF-I and IGF-II share similar molecular structures and biologic functions, their actions are regulated by distinct mechanisms (3). IGF-I is the dominant IGF signal in postnatal growth and maintenance, while IGF-II exerts actions mainly in prenatal development and fetal growth. Growth hormone regulates the activity of IGF-I, but has little effect on IGF-II. IGF-II is regulated primarily through paracrine and autocrine mechanisms. The IGF-II gene has four promoters, and each initiates a promoter-specific transcript which is expressed in a temporal and spatial-dependent manner (4-6). Three of the four IGF-II promoters, promoters 2, 3 and 4 (P2, P3 and P4), are located in a $\mathrm{CpG}$ island, and DNA methylation regulates their transcription (7). Given the presence of genomic imprinting and promoter specific transcription, epigenetic regulation plays an important role in control of IGF-II activities (8).

Studies have shown that IGF-II expression is elevated in ovarian cancer and high expression is associated with aggressive tumors $(9,10)$. The possible involvement of IGF-II 
in ovarian cancer has also been observed in our study in which we found high IGF-II expression associated with poor outcomes of the disease (11). Our investigation also indicates that the association between IGF-II expression and ovarian cancer survival was driven by two specific promoters, $\mathrm{P} 3$ and $\mathrm{P} 4$; the expression of $\mathrm{P} 1$ and $\mathrm{P} 2$ had little impact on the disease outcomes (12). Promoter-specific expression is known to be regulated through DNA methylation. Aberrant methylation, such as hypomethylation of oncogenes and hypermethylation of tumor suppressor genes, is seen often in cancer. These epigenetic alterations are believed to play an important role in tumor progression (13). In a parallel study, we developed seven methylation-specific polymerase chain reaction (MSP) assays to analyze methylation patterns in three of the four IGF-II promoters, using 3 assays to cover P2 and 2 assays each for P3 and P4, and we found that DNA methylation varied from region to region and promoter to promoter, and that distinct methylation patterns among patients were associated with different tumor features and survival outcomes (14). Here we combined the methylation and expression data to further determine which methylation marker, i.e., regional methylation, promoter-specific methylation or methylation patterns in multiple promoters, was more relevant to IGF-II expression and ovarian cancer progression.

\section{Materials and methods}

Study subjects. A clinical study of epithelial ovarian cancer was conducted in the Gynecologic Oncology Unit at University of Turin between October 1991 and February 2000. The study was approved by the university's ethics review committee. During the study, fresh tumor samples were collected from 211 patients who underwent surgery for primary epithelial ovarian cancer. The average age of patients at surgery was 57.6 years, and the range was between 26 and 82 years. Of the patients, 203 were followed after surgery through June 2001. The median follow-up time was 31.1 months, ranging from 0.6 to 114 months. Disease stage was determined based on the FIGO criteria (the International Federation of Gynecologists and Obstetricians); stage I through IV diseases were found in 52 (24.8\%), 12 (5.7\%), $132(62.9 \%)$ and $14(6.7 \%)$ patients, respectively. Serous tumors were present in $40.3 \%$ of the patients. The remaining were endometrioid (19.4\%), undifferentiated $(17.1 \%)$, mucinous $(8.5 \%)$, clear cell $(7.6 \%)$, mullerian $(6.6 \%)$ and other $(0.5 \%)$. Tumor grades (WHO criteria) from 1 (well differentiated) to 3 (poorly differentiated) were seen in $16.2,19.0$ and $64.8 \%$ of the patients, respectively. Of the patients who underwent a cytoreduction procedure, $107(51.7 \%)$ achieved optimal debulking, while $100(48.3 \%)$ had suboptimal results $(\geq 1 \mathrm{~cm}$ of detectable residual lesions remained after surgery). Patient responses to post-surgical treatment were classified into four categories, including i) complete response if there was resolution of all evidence of disease for at least one month, ii) partial response if there was a decrease of $\geq 50 \%$ in the product of the maximal and minimal diameters of all measurable lesions without the development of new lesions for at least one month, iii) stable disease if there was a decrease of $<50 \%$ or an increase of $<25 \%$ in the product of the diameters of all measurable lesions and iv) progressive disease if there was an increase of $\geq 25 \%$ in the product of the diameters of all measurable lesions or the presence of new lesions. When analyzed, patients with partial response, no response or disease progression were grouped together as others $(n=56)$ which were compared to patients who had complete response $(n=142)$.

Isolation and analysis of tissue DNA and RNA. Fresh tumor samples were collected during surgery. The specimens were snap-frozen in liquid nitrogen immediately after resection and stored at $-80^{\circ} \mathrm{C}$ until analysis. The tissue samples were examined independently by two pathologists to confirm tumor content. The majority of samples contained $80-90 \%$ tumor cells. Tumor tissues were pulverized manually in liquid nitrogen, and $100 \mathrm{mg}$ tissue powder each was processed to extract DNA and total RNA following standard phenolchloroform protocols. One microgram of total RNA was converted to cDNA using the Cloned AMV First-Strand cDNA Synthesis kit (Invitrogen, Carlsbad, CA). To measure cytosine methylation, DNA samples were treated with sodium bisulfite to convert unmethylated cytosine to thymine, while keeping methylated cytosine unchanged. Modified DNA samples were then purified and analyzed with methylation specific PCR (MSP). Seven MSP assays were developed to analyze $\mathrm{CpG}$ site methylation in three IGF-II promoters, including 3 assays for promoter 2, and 2 assays each for promoters 3 and 4. Detailed information on these assays was provided elsewhere (14).

Five IGF-II transcripts, including one from each of the IGF-II promoters (P1, P2, P3 and P4) and a common region shared by all the transcripts, were analyzed in tumor samples using the SYBR green-based quantitative PCR. The real-time PCR was performed using the Chromo4 continuous fluorescence detector system (MJ Research, Inc., Waltham, MA). The PCR primers for IGF-II transcripts were designed using the Primer Expression software (Applied Biosystems, Foster City, CA). The primer sequences and PCR conditions were published elsewhere $(11,12,15)$. Glyceraldehyde-3-phosphate dehydrogenase (GAPDH) was used as reference. Each sample was analyzed in triplicates, and the measurements with coefficient variation $(\mathrm{CV})>10 \%$ were discarded, using only two close measurements. A melting curve was generated after each PCR run to determine the size of PCR product.

Extraction of tissue proteins and analysis of IGF-II peptide. Tissue protein extract was prepared for analysis of IGF-II peptide in tumor samples. Pulverized tissue powder (10$230 \mathrm{mg}$ ) were mixed with $1 \mathrm{ml}$ BD Talon X Tractor buffer (Clontech, Palo Alto, CA), and were centrifuged at $14000 \mathrm{rpm}$ for $30 \mathrm{~min}$ at $4^{\circ} \mathrm{C}$. After centrifugation, the supernatant was collected for measuring levels of total proteins and IGF-II peptide. Concentrations of total proteins were measured using the bicinchoninic acid method (Pierce Inc., Rockford, IL). Levels of IGF-II peptide were determined with a commercial kit which is an enzyme-linked immunosorbent assay (ELISA) (Diagnostic Laboratories Systems, Webster, TX). The tumor samples were tested in duplicate, and the test results with $\mathrm{CV}>10 \%$ were repeated. IGF-II concentrations in tumor samples were adjusted for total proteins.

Statistical analysis. Methylation status was analyzed both individually based on each MSP assay as well as jointly for each promoter. In the assessment of promoter methylation, 


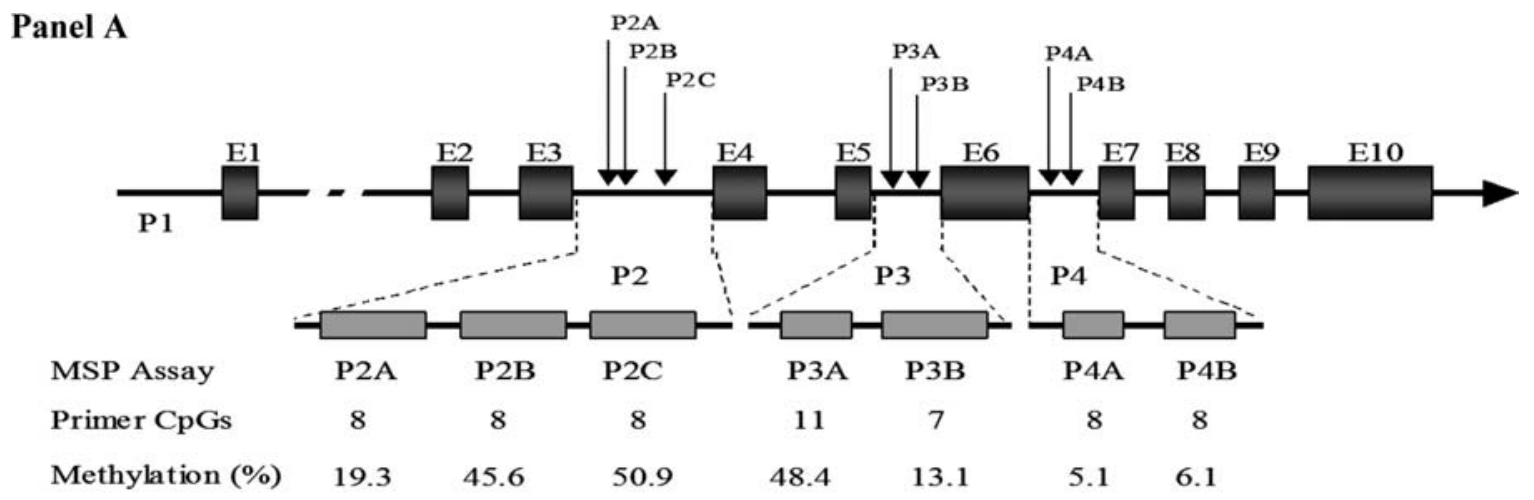

\section{Panel B}
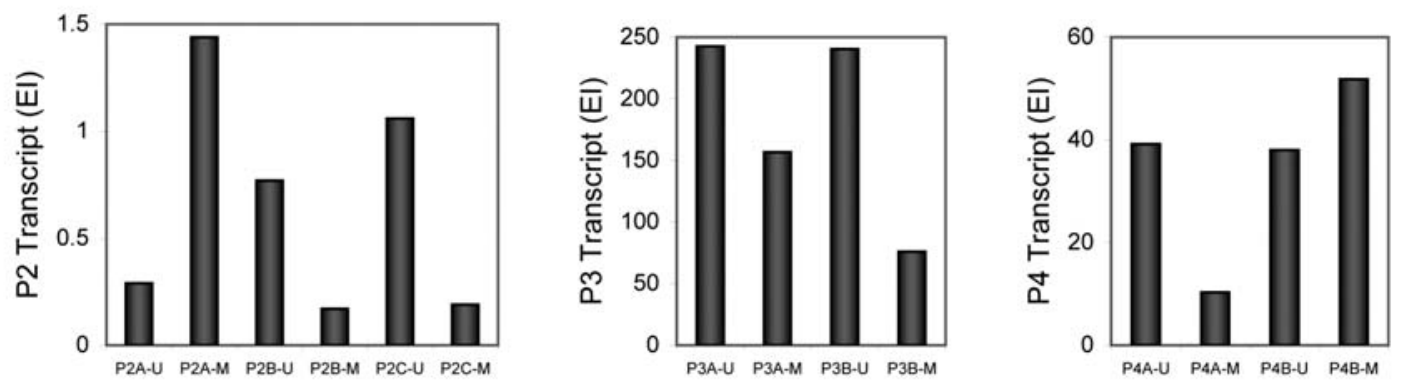

Panel C
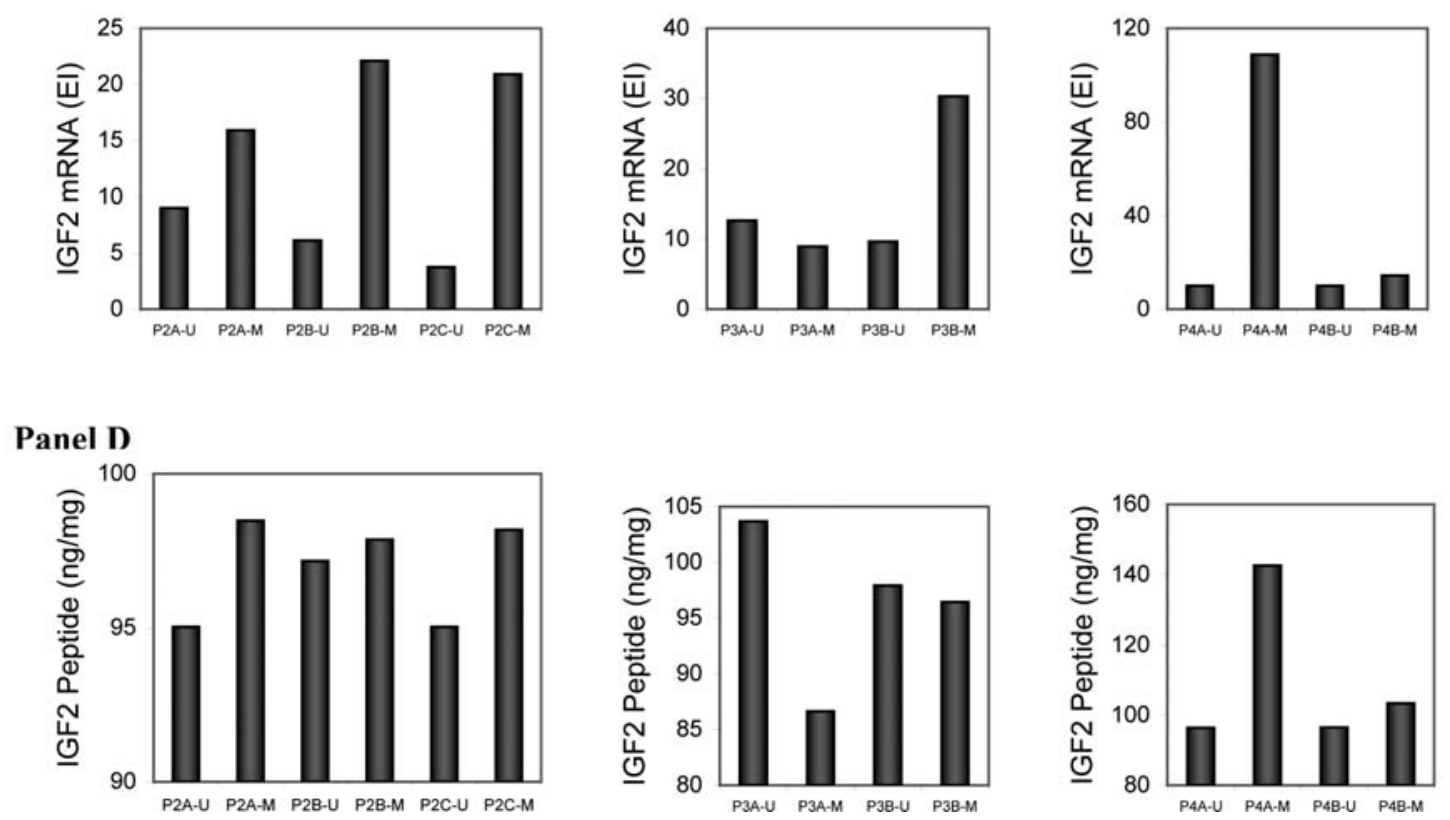

Figure 1. The structure and methylation of the IGF-II gene (Panel A), median expression of IGF-II promoter-specific mRNA in methylated and unmethylated samples (Panel B), median expression of IGF-II mRNA in the common region shared by all IGF-II transcripts in methylated and unmethylated samples (Panel C), and median IGF-II peptide concentrations in methylated and unmethylated samples (Panel D). Note: E1-E10 in Panel A represent 10 IGF-II exons. P1-P4 in Panel A represent 4 IGF-II promoters. P2A-P4B in Panel A represent 7 MSP assays. EI, expression index. P2A-U and P2A-M represent unmethylated and methylated samples measured by P2A MSP assay. P2B-U and P2B-M represent unmethylated and methylated samples measured by P2B MSP assay. P2C-U and P2C-M represent unmethylated and methylated samples measured by P2C MSP assay. P3A-U and P3A-M represent unmethylated and methylated samples measured by P3A MSP assay. P3B-U and P3B-M represent unmethylated and methylated samples measured by P3B MSP assay. P4A-U and P4A-M represent unmethylated and methylated samples measured by P4A MSP assay. P4B-U and P4B-M represent unmethylated and methylated samples measured by P4B MSP assay.

methylation status was determined by the positive results of any MSP assays designed for the promoter. For example, if one of the three MSP assays for P2 was positive, P2 was considered methylated. Promoter methylation was also analyzed in combination. Given that little methylation was found in P4, combined analysis was performed only for P2 and P3. Three categories of $\mathrm{P} 2$ and $\mathrm{P} 3$ combination were created, including i) methylated $\mathrm{P} 2$ and unmethylated $\mathrm{P} 3$ (P2M/P3U), ii) 
Panel A

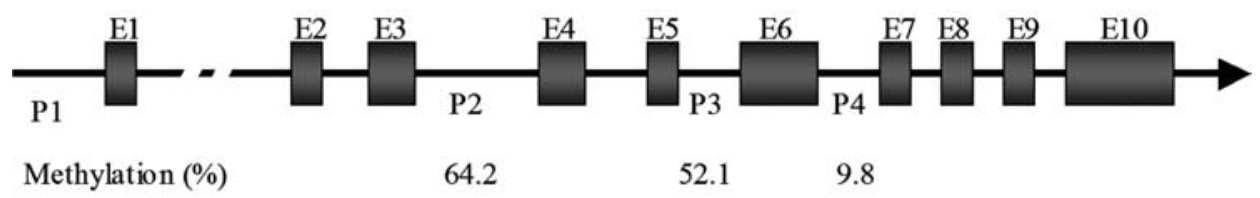

Panel B
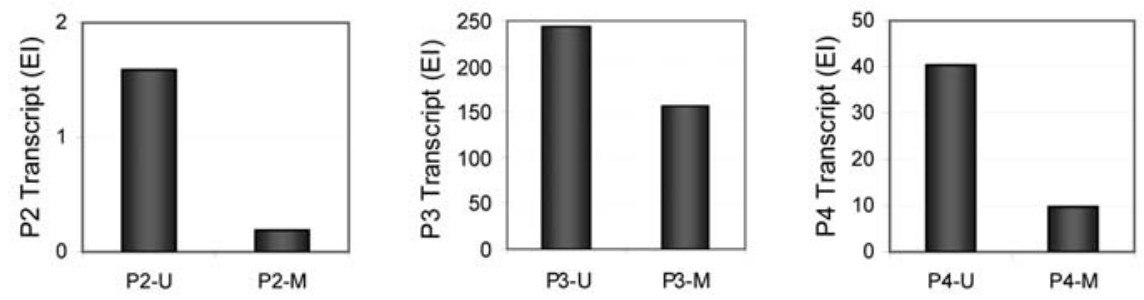

Panel C
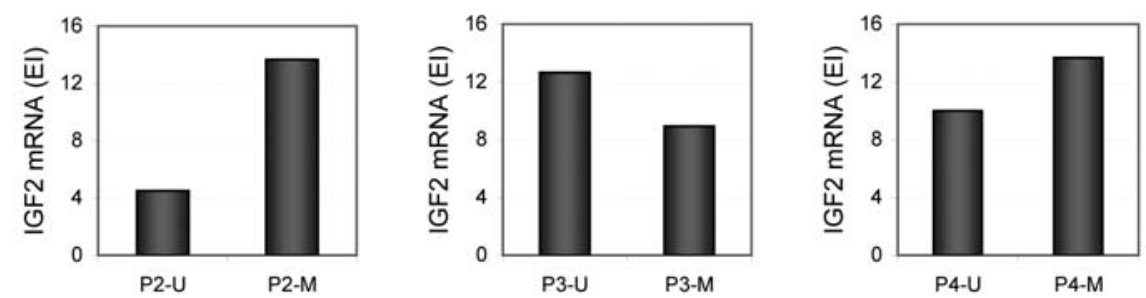

\section{Panel D}
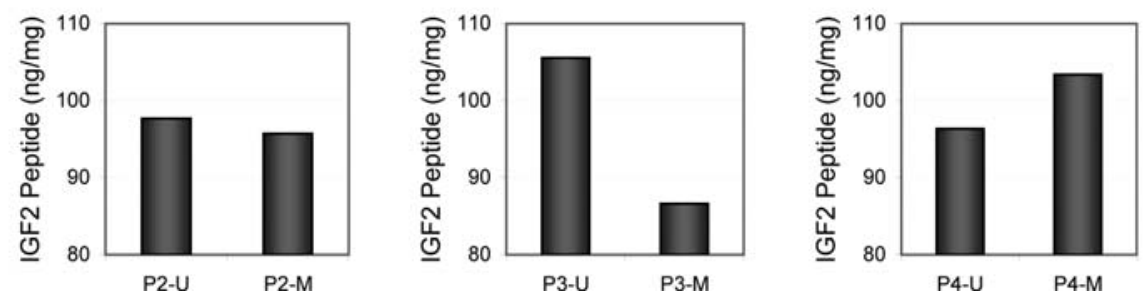

Figure 2. The structure and methylation of the IGF-II gene (Panel A), median expression of IGF-II promoter-specific mRNA in methylated and unmethylated samples (Panel B), median expression of IGF-II mRNA in the common region shared by all IGF-II transcripts in methylated and unmethylated samples (Panel C), and median IGF-II peptide concentrations in methylated and unmethylated samples (Panel D). Note: E1-E10 in Panel A represent 10 IGF-II exons. P1-P4 in Panel A represent 4 IGF-II promoters. EI, expression index. P2-U and P2-M represent unmethylated and methylated P2. P3-U and P3-M represent unmethylated and methylated P3. P4-U and P4-M represent unmethylated and methylated P4.

unmethylated P2 and methylated P3 (P2U/P3M) and iii) a mixed group which included those who did not fit to the first two groups. For mRNA expression, an expression index (EI) was computed using the formula: $1000 \times 2^{(-\Delta \mathrm{Ct})}$, where $\Delta \mathrm{Ct}=$ $\mathrm{Ct}_{\mathrm{IGF-II}}-\mathrm{Ct}_{\mathrm{GAPDH}} \cdot \chi^{2}$ tests were used to analyze IGF-II methylation and expression in association with clinical and pathological features of ovarian cancer. Kaplan-Meier survival curves were constructed to show survival differences by IGF-II methylation patterns and expression levels. Univariate and multivariate survival analyses were also performed using the Cox proportional hazards regression model to examine the risk of disease progression and death in association with IGF-II expression and methylation. In the association analyses, IGF-II levels, either RNA expression or peptide concentration, were classified into low, medium and high groups based on tertile distributions. All analyses were done using SAS version 9.1 (SAS Institute, Cary, NC).

\section{Results}

IGF-II expression by each methylation specific PCR assay. Fig. 1 shows from top to bottom: the IGF-II gene structure, regions analyzed by the seven MSP assays, numbers of $\mathrm{CpG}$ sites covered by the MSP primers, percentages of methylation in each assay (Panel A); levels of promoter-specific expression of IGF-II mRNA from P2 to P4 in methylated and unmethylated samples (Panel B); expression levels of the common region of IGF-II mRNA in methylated and unmethylated samples (Panel C); and peptide concentrations of IGF-II in methylated and unmethylated samples (Panel D). We found that methylation status in the analyzed regions of IGF-II varied from low to high $(19.3 \%$ in $\mathrm{P} 2 \mathrm{~A}, 45.6 \%$ in $\mathrm{P} 2 \mathrm{~B}$ and $50.9 \%$ in $\mathrm{P} 2 \mathrm{C})$ and then high to low (48.4\% in $\mathrm{P} 3 \mathrm{~A}, 13.1 \%$ in $\mathrm{P} 3 \mathrm{~B}, 6.1 \%$ in $\mathrm{P} 4 \mathrm{~B}$ and $5.1 \%$ in $\mathrm{P} 4 \mathrm{~A}$ ) from $\mathrm{P} 2$ to $\mathrm{P} 4$ (Panel A). Methylation status in 5 of the 7 assays appeared to be related 
Panel A

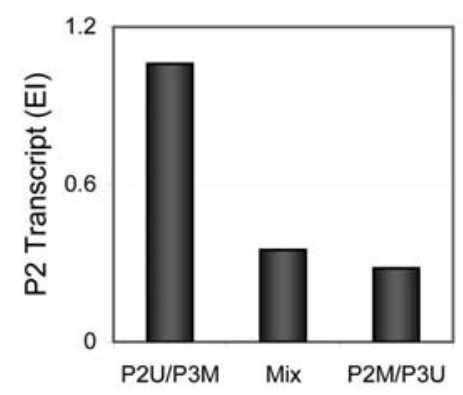

Panel C

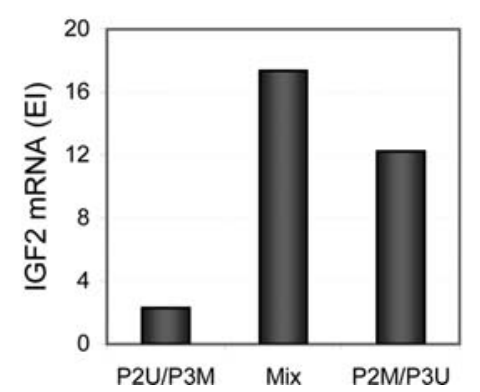

Panel B

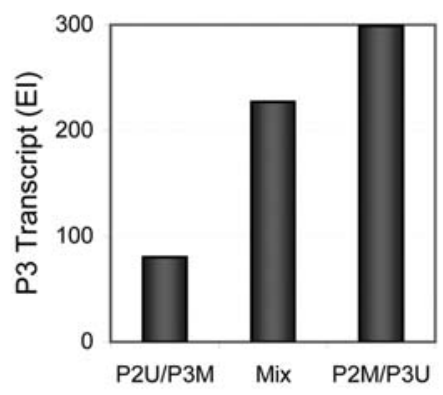

Panel D

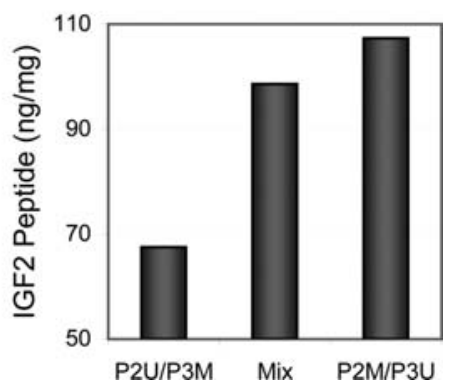

Figure 3. Median expression of IGF-II promoter-specific mRNA (Panels A and B), median expression of common IGF-II mRNA region (Panel C) and median peptide concentrations (Panel D) by different methylation patterns in P2 and P3. EI, expression index. P2U/P3M represents unmethylated P2 and methylated P3. P2M/P3U represents methylated P2 and unmethylated P3. Mix includes methylation patterns other than P2U/P3M or P2M/P3U.

to promoter-specific transcripts (Panel B), i.e., unmethylated promoters having higher expression than methylated promoters. Two regions that were not matched well between methylation and expression were the beginning and end of the $\mathrm{CpG}$ islands covered by $\mathrm{P} 2 \mathrm{~A}$ and $\mathrm{P} 4 \mathrm{~B}$ assays. Overall, promoter methylation did seem to affect promoter-specific expression. However, when we further examined the effect of each methylation assay status on overall IGF-II transcripts, we did not observe a trend correlation between promoterspecific methylation and IGF-II expression (Panel C). IGF-II peptide concentrations appeared to be affected only by methylation in P3 as levels of IGF-II peptide were higher in unmethylated than in methylated P3 (Panel D). Assessing IGF-II expression from Panels B-D together, P3A seemed to be the only assay in which the methylation status was relevant to expression.

IGF-II expression by promoter methylation and methylation pattern. Methylation status was also determined based on the results of MSP in each promoter as described earlier. Promoter methylation was found in $64.2 \%$ of P2, $52.1 \%$ of P3 and $9.8 \%$ of P4 (Fig. 2, Panel A). IGF-II mRNA expression was higher in unmethylated than in methylated tumor samples in a promoter-specific fashion (Panel B). IGF-II expression in unmethylated and methylated P2, P3 and P4 were 1.59 EI vs. 0.19 EI, 242.60 EI vs. 156.61 EI and 40.41 EI vs. 9.75 EI, respectively. The expression of the common mRNA region was related to methylation only in $\mathrm{P} 3$, not in $\mathrm{P} 2$ or $\mathrm{P} 4$ (Panel C). Levels of IGF-II peptide were also higher in unmethylated than in methylated P3 (Panel D).
Methylation patterns in P2 and P3 were also analyzed for their effect on IGF-II expression. The analysis showed that the methylation pattern of $\mathrm{P} 2$ and $\mathrm{P} 3$ was substantially associated with IGF-II expression (Fig. 3). The expression of P3 (Panel B), common mRNA region (Panel C) and IGF-II peptide (Panel D) were all substantially lower in the samples with unmethylated P2 and methylated P3 (P2U/P3M) than in those with methylated P2 and unmethylated P3 (P2M/P3U), 80.12 EI vs. $299.03 \mathrm{EI}, 2.30 \mathrm{EI}$ vs. $12.25 \mathrm{EI}$ and $67.53 \mathrm{ng} / \mathrm{mg}$ vs. $107.30 \mathrm{ng} / \mathrm{mg}$, respectively. For P2 expression, the relationship was opposite, high expression in P2U/P3M and low in P2M/P3U (Panel A). The effect of methylation on IGF-II expression seemed to be more evident when using the methylation pattern as compared to methylation status of individual assay or promoter.

Associations of IGF-II methylation and expression with clinical and pathological features. Given the strong connection between methylation pattern and expression, we analyzed the associations of methylation pattern with clinical and pathological features of ovarian cancer, and compared the results with IGF-II mRNA expression and peptide concentrations (Table I). Of the three IGF-II markers (methylation pattern, mRNA and peptide), mRNA expression appeared to be the most significant one, which had significant associations with five of the six disease features, including disease stage (Stage I/II vs. III/ IV), tumor grade (Grade 1/2 vs. 3), tumor histology (non-serous vs. serous), debulking result (optimal vs. suboptimal) and residual tumor size ( 0 vs. $>0$ ). High IGF-II mRNA expression was seen more often in patients with advanced stages (39.9 
Table I. Associations of IGF-II expression and methylation pattern with clinical features of ovarian cancer.

\begin{tabular}{|c|c|c|c|c|c|c|c|c|c|}
\hline \multirow[b]{2}{*}{ Variables } & \multicolumn{3}{|c|}{ IGF-II methylation pattern } & \multicolumn{3}{|c|}{ IGF-II mRNA expression } & \multicolumn{3}{|c|}{ IGF-II peptide concentration } \\
\hline & P2UP3M & Mix & P2MP3U & Low & Medium & High & Low & Medium & High \\
\hline \multicolumn{10}{|l|}{ Disease stage } \\
\hline I-II & $9(14.1)$ & $43(67.2)$ & $12(18.7)$ & $29(50.00)$ & $18(31.03)$ & $11(18.97)$ & $29(46.03)$ & $14(22.22)$ & $20(31.75)$ \\
\hline III-IV & $16(11.2)$ & $88(61.5)$ & $39(27.3)$ & $38(26.57)$ & $48(33.57)$ & $57(39.86)$ & $40(27.59)$ & $56(38.62)$ & $49(33.79)$ \\
\hline P-value & 0.401 & & & $0.002^{\mathrm{a}}$ & & & $0.018^{\mathrm{a}}$ & & \\
\hline \multicolumn{10}{|l|}{ Grade } \\
\hline 1 and 2 & $13(17.8)$ & $49(67.1)$ & $11(15.1)$ & $30(44.12)$ & $23(33.82)$ & $15(22.06)$ & $23(31.08)$ & $33(44.59)$ & $18(24.32)$ \\
\hline 3 & $12 \quad(9.0)$ & $82(61.2)$ & $40(29.8)$ & $37(27.82)$ & $43(32.33)$ & $53(39.85)$ & $46(34.33)$ & $37(27.61)$ & $51(38.06)$ \\
\hline $\mathrm{P}$-value & $0.023^{\mathrm{a}}$ & & & $0.020^{\mathrm{a}}$ & & & $0.031^{\mathrm{a}}$ & & \\
\hline \multicolumn{10}{|c|}{ Histological type } \\
\hline Non-serous & $16(12.8)$ & $81(64.8)$ & $28(22.4)$ & $48(39.67)$ & $42(34.71)$ & $31(25.62)$ & $46(36.22)$ & $38(29.92)$ & $43(33.86)$ \\
\hline Serous & $9(10.8)$ & $51(61.5)$ & $23(27.7)$ & $19(23.46)$ & 25 (30.86) & $37(45.68)$ & $23(28.05)$ & $32(39.02)$ & $27(32.93)$ \\
\hline $\mathrm{P}$-value & 0.663 & & & $0.007^{\mathrm{a}}$ & & & 0.324 & & \\
\hline \multicolumn{10}{|l|}{ Debulk results } \\
\hline Optimal & $19(17.9)$ & $65(61.3)$ & $22(20.8)$ & $40(40.40)$ & $35(35.35)$ & $24(24.24)$ & $41(38.68)$ & $35(33.02)$ & $30(28.30)$ \\
\hline Suboptimal & $6 \quad(6.1)$ & $63(64.3)$ & $29(29.6)$ & $26(26.26)$ & $30(30.30)$ & $43(43.43)$ & $26(26.26)$ & $35(35.35)$ & $38(38.38)$ \\
\hline P-value & $0.024^{\mathrm{a}}$ & & & $0.013^{\mathrm{a}}$ & & & 0.131 & & \\
\hline \multicolumn{10}{|c|}{ Residual tumor size } \\
\hline 0 & $16(18.0)$ & $56(62.9)$ & $17(19.1)$ & $37(44.05)$ & $28(33.33)$ & $19(22.62)$ & $36(40.45)$ & $25(28.09)$ & $28(31.46)$ \\
\hline$>0$ & $9 \quad(7.9)$ & $72(63.1)$ & $33(29.0)$ & $29(25.66)$ & 37 (32.74) & 47 (41.59) & $31(26.96)$ & $45(39.13)$ & $39(33.91)$ \\
\hline P-value & $0.048^{\mathrm{a}}$ & & & $0.007^{\mathrm{a}}$ & & & 0.098 & & \\
\hline \multicolumn{10}{|c|}{ Treatment response } \\
\hline Complete & $22(15.4)$ & $91(63.6)$ & $30(21.0)$ & $48(35.29)$ & $49(36.03)$ & $39(28.68)$ & $52(36.62)$ & $49(34.51)$ & $41(28.87)$ \\
\hline $\begin{array}{l}\text { Partial or } \\
\text { progression }\end{array}$ & $3 \quad(5.6)$ & $32(59.3)$ & $19(35.2)$ & $15(27.27)$ & $16(29.09)$ & $24(43.64)$ & $12(21.43)$ & $19(33.93)$ & $25(44.64)$ \\
\hline P-value & $0.043^{\mathrm{a}}$ & & & 0.137 & & & 0.053 & & \\
\hline
\end{tabular}

${ }^{\mathrm{a}} \mathrm{p}<0.05$

vs. $19.0 \%, \mathrm{p}=0.002)$, high grade tumors (39.9 vs. $22.1 \%$, $\mathrm{p}=0.020$ ), serous histology (45.7 vs. $25.6 \%, \mathrm{p}=0.007)$, suboptimal debulking (43.4 vs. $24.2 \%, \mathrm{p}=0.013$ ) or larger residual tumor (41.6 vs. $22.6 \%, \mathrm{p}=0.007$ ). Methylation pattern was associated with four of the six disease features, including tumor grade, debulking result, residual tumor size and response to treatment. Compared to tumors with P2U/P3M, those with $\mathrm{P} 2 \mathrm{M} / \mathrm{P} 3 \mathrm{U}$ (associated with high IGF-II expression) were more likely to have high grade ( 29.8 vs. $15.1 \%, p=0.023)$, suboptimal debulking ( 29.6 vs. $20.8 \%, \mathrm{p}=0.024)$, large residual tumor (29.0 vs. $19.1 \%, \mathrm{p}=0.048)$ and no complete response to treatment ( 35.2 vs. $21.0 \%, \mathrm{p}=0.043)$. IGF-II peptide concentration was associated with fewer disease features than mRNA expression or methylation pattern; only 2 of the 6 disease features were related to IGF-II peptide levels, including disease stage $(33.8$ vs. $31.8 \%, \mathrm{p}=0.018)$ and tumor grade (38.1 vs. $24.3 \%, \mathrm{p}=0.031$ ).

Associations of IGF-II methylation and expression with survival outcomes. Associations of patient survival with IGF-II methylation and expression are shown in Table II. Similar to the findings of disease features, IGF-II mRNA expression was the most significant marker in relation to patient survival. High IGF-II expression was associated with both progressionfree and overall survival of ovarian cancer patients. Patients with high levels of IGF-II mRNA expression had increased risks for disease progression $(\mathrm{HR}=1.71,95 \% \mathrm{CI}$ : $1.03-2.84)$ and death $(\mathrm{HR}=2.19,95 \% \mathrm{CI}: 1.30-3.68)$ compared to those with low expression. Promoter methylation pattern was also significantly associated with progression-free survival. Patients with P2M/P3U (high IGF-II expression) had over 2-fold increases in risk of disease progression compared to those with P2U/P3M (HR=2.59, 95\% CI: 1.13-5.94). However, unlike mRNA expression, an association between methylation pattern and overall survival was not observed. No associations were statistically significant after adjusting for patient age at surgery, disease stage, tumor grade and histology, suggesting that these markers may have limited value to serve as independent prognostic indicators. IGF-II peptide concentration was not associated with either 
Table II. Associations of IGF-II expression and methylation pattern with ovarian cancer survival.

\begin{tabular}{|c|c|c|c|c|}
\hline Survival outcome & Level & $\begin{array}{c}\text { IGF-II methylation } \\
\text { pattern } \\
\operatorname{HR}^{\mathrm{b}}\left(95 \% \mathrm{CI}^{\mathrm{c}}\right)\end{array}$ & $\begin{array}{l}\text { IGF-II mRNA } \\
\text { expression } \\
\text { HR }(95 \% \text { CI })\end{array}$ & $\begin{array}{l}\text { IGF-II peptide } \\
\text { concentration } \\
\text { HR }(95 \% \mathrm{CI})\end{array}$ \\
\hline \multicolumn{5}{|l|}{ Disease progression } \\
\hline \multirow[t]{4}{*}{ Unadjusted model } & Low & 1 & 1 & 1 \\
\hline & Medium & $2.04(0.93-4.46)$ & $1.42(0.86-2.36)$ & $1.14(0.68-1.90)$ \\
\hline & High & $2.59(1.13-5.94)$ & $1.71(1.03-2.84)$ & $1.41(0.85-2.35)$ \\
\hline & $\mathrm{P}$-value for trend & 0.026 & 0.036 & 0.180 \\
\hline \multirow[t]{4}{*}{ Adjusted model ${ }^{\mathrm{d}}$} & Low & 1 & 1 & 1 \\
\hline & Medium & $1.90(0.85-4.24)$ & $1.41(0.84-2.35)$ & $1.01(0.60-1.71)$ \\
\hline & High & $2.20(0.93-5.22)$ & $1.32(0.79-2.20)$ & $1.42(0.85-2.37)$ \\
\hline & $\mathrm{P}$-value for trend & 0.104 & 0.286 & 0.171 \\
\hline \multicolumn{5}{|l|}{ Death } \\
\hline \multirow[t]{4}{*}{ Unadjusted model } & Low & 1 & 1 & 1 \\
\hline & Medium & $1.61(0.77-3.37)$ & $1.63(0.97-2.76)$ & $1.02(0.60-1.75)$ \\
\hline & High & $1.74(0.78-3.88)$ & $2.19(1.30-3.68)$ & $1.53(0.92-2.56)$ \\
\hline & $\mathrm{P}$-value for trend & 0.225 & 0.003 & 0.086 \\
\hline \multirow[t]{4}{*}{ Adjusted model ${ }^{\mathrm{d}}$} & Low & 1 & 1 & 1 \\
\hline & Medium & $1.46(0.68-3.10)$ & $1.56(0.91-2.66)$ & $0.94(0.54-1.65)$ \\
\hline & High & $1.54(0.66-3.62)$ & $1.63(0.96-2.76)$ & $1.49(0.89-2.50)$ \\
\hline & P-value for trend & 0.392 & 0.070 & 0.103 \\
\hline
\end{tabular}

${ }^{a}$ Methylation pattern, P2UP3M is labeled as low (reference), mixed is medium and P2MP3U is high. ${ }^{b} \mathrm{HR}$, hazards ratio. ${ }^{\mathrm{C}} \mathrm{CI}$, confidence interval. ${ }^{\mathrm{d}}$ Adjusted for age, stage, grade and histotype.

progression-free or overall survival in the analysis. Similar results were also demonstrated in the Kaplan-Meier survival curves (Figs. 4 and 5). Progression-free survival curves were significantly different by methylation patterns $(\mathrm{p}=0.025)$ and mRNA expression levels $(\mathrm{p}=0.036)$; no differences were observed by IGF-II peptide concentrations ( $\mathrm{p}=0.179$ ) (Fig. 4). For overall survival, significant differences were only seen in patients with different levels of mRNA expression $(\mathrm{p}=0.003)$; survival curves were not significantly different by methylation patterns $(\mathrm{p}=0.225)$ or peptide concentrations ( $\mathrm{p}=0.087)$ (Fig. 5).

\section{Discussion}

The study showed different levels of methylation in ovarian cancer across a large $\mathrm{CpG}$ island in the IGF-II gene. Methylation levels also varied among three IGF-II promoters in ovarian cancer with high methylation in P2 and P3 and low in P4. As expected, methylation in most of the analyzed region (5 of the $7 \mathrm{MSP}$ assays) was related to the expression of IGF-II mRNA, i.e., low expression in methylated samples and high in unmethylated ones. Considering the assay results together based on each promoter, we found a similar trend of lower expression in methylated than in unmethylated promoters. While promoter-specific methylation matched well to mRNA expression at the corresponding promoter, the expression of the common region of IGF-II mRNA was correlated only to P3 methylation. P2 and P4 methylation did not match to the common region expression. Similar results were also observed for IGF-II peptide. These observations suggest that methylation regulation of P3 activity may be important for IGF-II action in ovarian cancer. Our study showed that P3 transcripts also had the highest level of expression in ovarian tumors, indicating that $\mathrm{P} 3$ expression may dominate the effect of IGF-II on the disease. P3 and P4 are known as fetal promoters which are highly active during embryonic growth. Under normal circumstances, P3 and P4 activities are suppressed after birth and are kept silent throughout life $(5,16)$. These promoters, however, are found to be reactivated in cancer. Studies have shown elevated P3 expression in several malignancies (17-20), and P3 demethylation plays a critical role in reactivation of $\mathrm{P} 3$ expression $(21,22)$.

Our study showed that levels of IGF-II mRNA and peptide were substantially different among patients with distinct methylation patterns in P2 and P3. Patients with methylated P2 and unmethylated P3 (P2M/P3U) had 5 times higher mRNA expression and nearly 2 times higher peptide levels compared to those with unmethylated P2 and methylated P3 (P2U/P3M). These differences in mRNA expression and peptide concentrations would be much smaller if we only 
Panel A

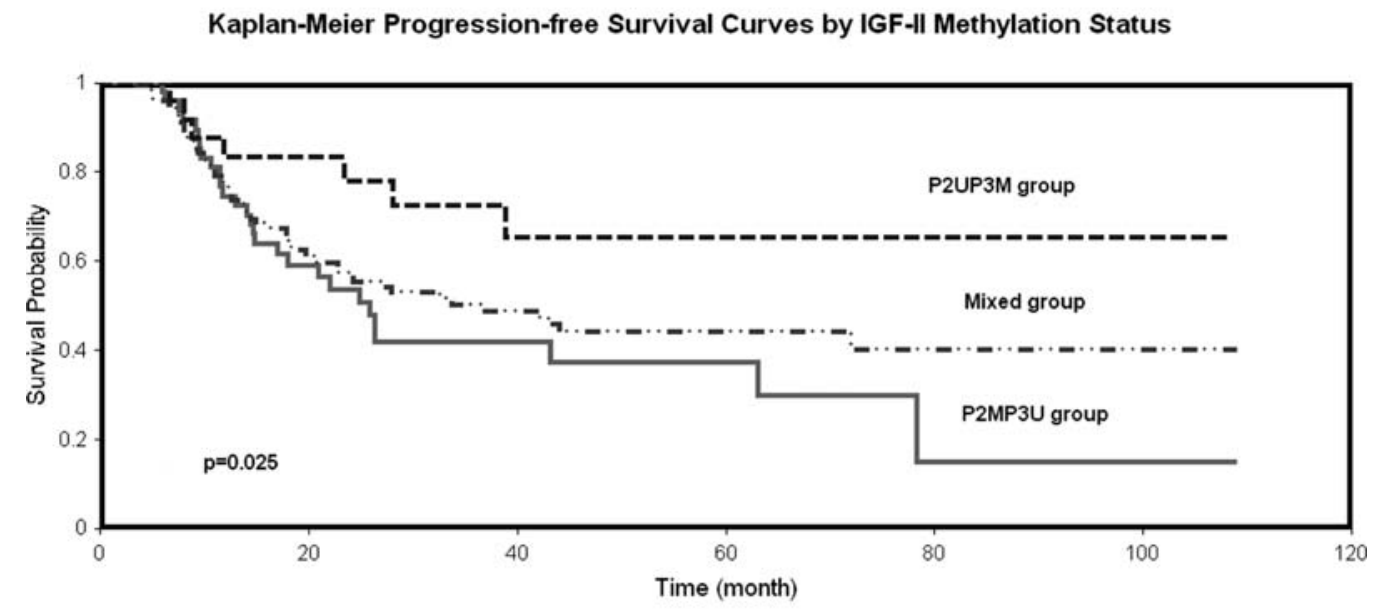

Panel B

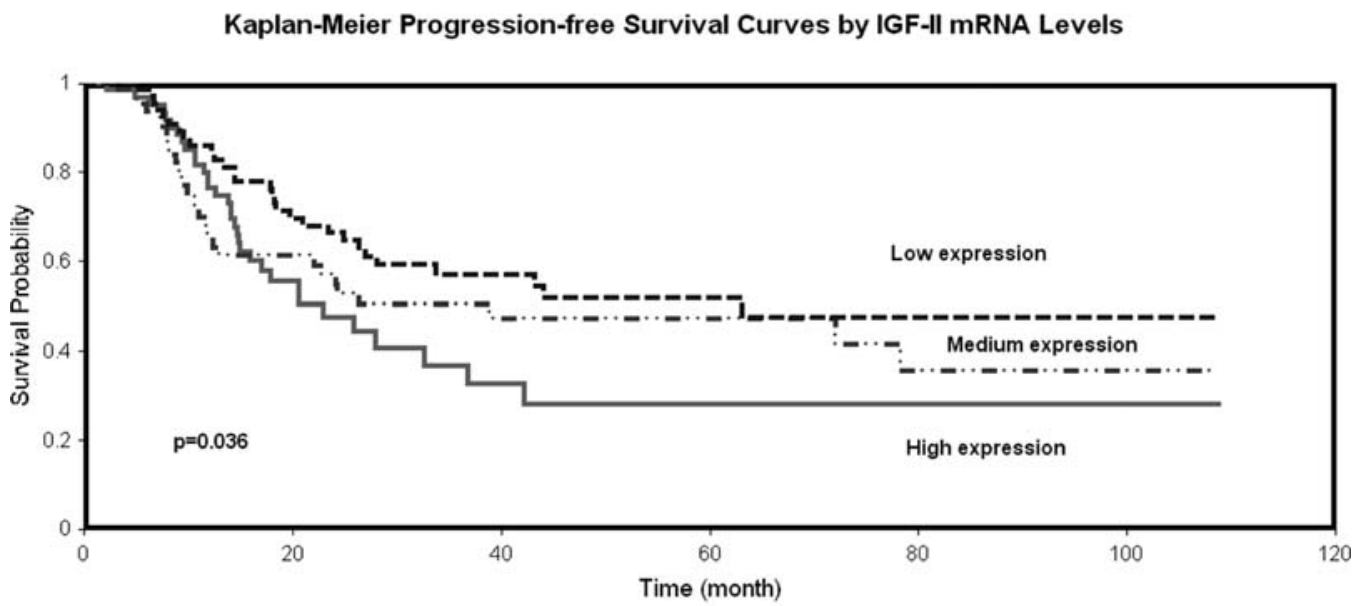

Panel C

Kaplan-Meier Progression-free Survival Curves by IGF-II Peptide Concentrations

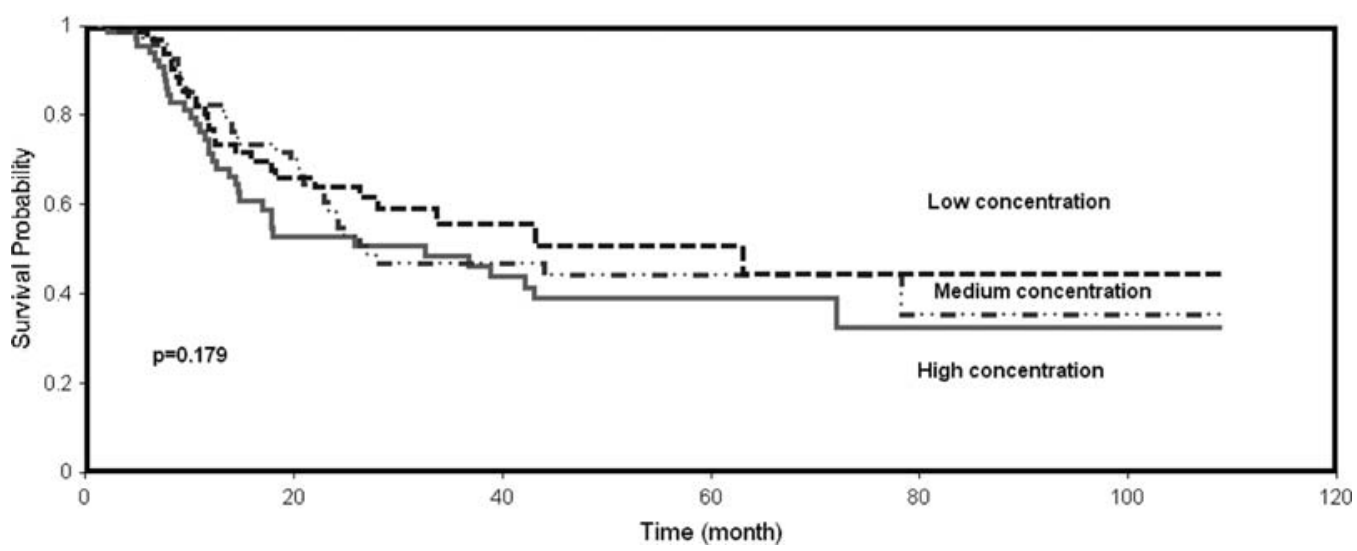

Figure 4. Kaplan-Meier disease progression-free survival curves by IGF-II promoter methylation patterns (Panel A), IGF-II mRNA levels (Panel B) and IGF-II peptide concentrations (Panel C).

assessed the methylation status of P2 or P3 individually. Furthermore, the methylation pattern was related to treatment response, whereas mRNA expression was not, suggesting that these molecular markers may have different implications for the disease. When assessing the associations of methylation markers with clinical and pathological features of ovarian cancer, we found that the methylation pattern between P2 and P3 was associated with several disease characteristics. Methylation at each individual assay or by each promoter was not as strongly associated with the disease as the methylation 
Panel A

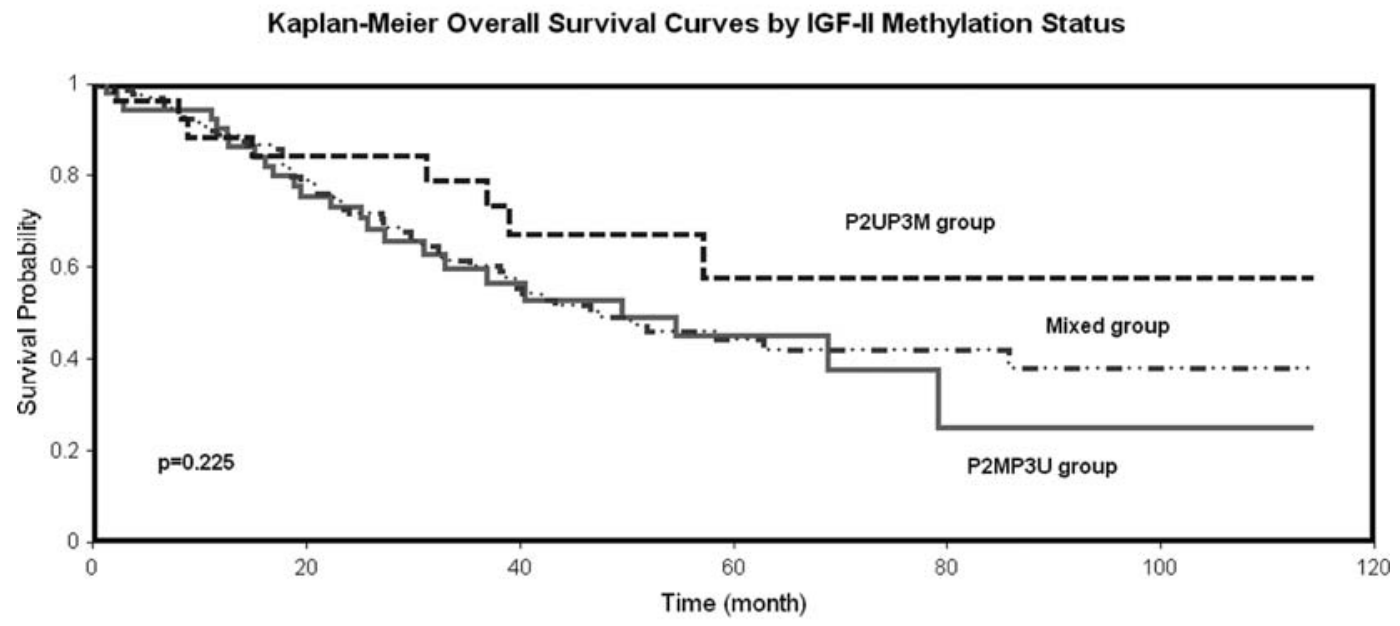

Panel B

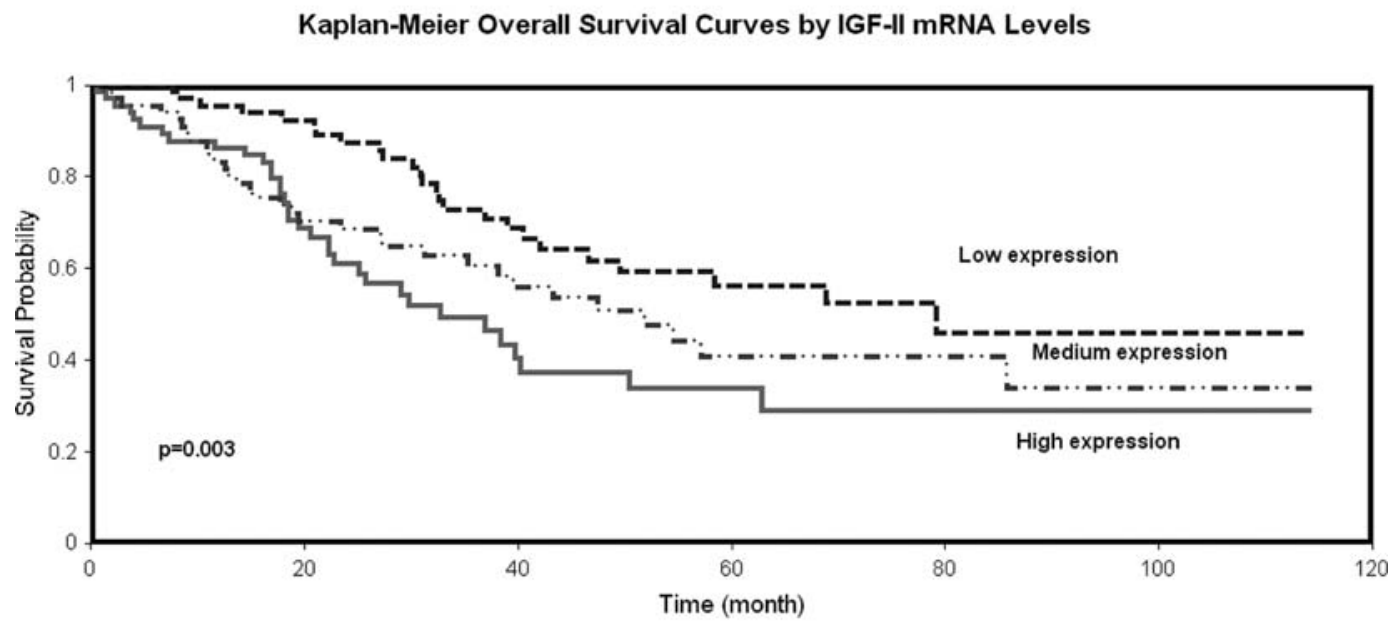

Panel C

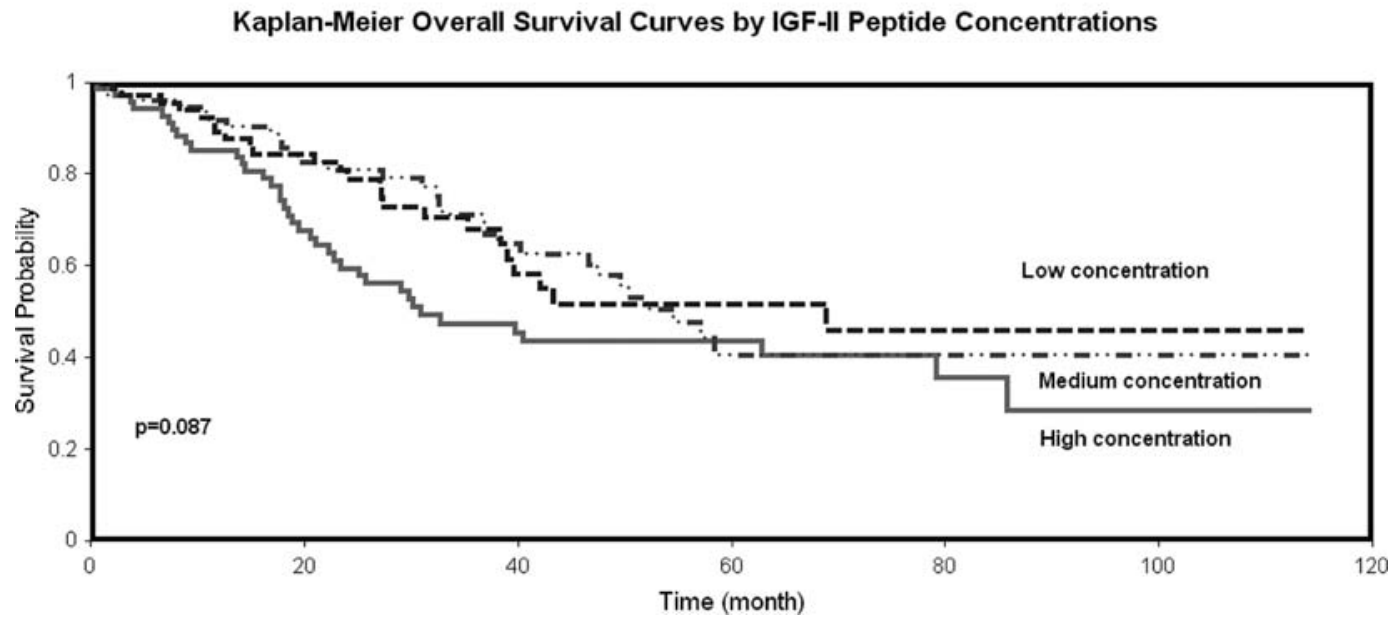

Figure 5. Kaplan-Meier overall survival curves by IGF-II promoter methylation patterns (Panel A), IGF-II mRNA levels (Panel B) and IGF-II peptide concentrations (Panel C).

pattern. Compared to IGF-II mRNA expression and peptide concentrations in the tumors, methylation patterns in $\mathrm{P} 2$ and P3 seemed to behave similarly to mRNA expression in their associations with tumor grade, debulking results and residual tumor size. These findings suggest that a methylation pattern in IGF-II promoters is clinically relevant and may have potential implication in disease management. Other studies have shown that many methylation markers in tumor tissues 
are detectable in serum cell-free DNA $(23,24)$. This unique aspect of serum DNA analysis provides a potential opportunity of using blood samples, instead of tissue specimens, to analyze molecular features of cancer for disease management.

The IGF axis is known to play an important role in cancer. The effects of IGF-I on cancer development and tumor progression have been investigated extensively. Compared to IGF-I, the role of IGF-II in cancer has been less studied. IGF-II is considered to be less important than IGF-I because of their differences in mitogenic potency and interaction with environmental and lifestyle factors. However, IGF-II is quite distinct from IGF-I with regard to the regulation of their activities. IGF-II is subject to extensive epigenetic regulation involving DNA methylation, which controls genomic imprinting and alternative use of different promoters for transcription (8). Aberrant methylation has been identified as an important molecular feature involved in tumorigenesis and disease progression. Previous studies have shown changes in the IGF-II promoter activities in liver cancer, and the change is related to the methylation in each promoter (21). Our study found similar evidence that supports the role of aberrant methylation in ovarian cancer. The agreement indicates that this epigenetic change may occur frequently in cancer and a common event may be important in the disease process. Further analysis of this growth factor with other members of the IGF family may help to improve our understanding of IGF's role in cancer. In this study, we also observed a correlation between IGFBP-3 expression and IGF-II methylation (data not shown). This relationship indicates that epigenetic regulation of IGF-II may affect not only the expression of IGF-II, but also possibly other members of the IGF family, either directly or indirectly.

In addition to fetal promoter activation, loss of imprinting (LOI) may also cause increases in IGF-II expression $(25,26)$. LOI in IGF-II has been found in a number of cancers, including Wilms' tumor, renal cell carcinoma, cervical cancer, gastric cancer, colon cancer, lung cancer, and head and neck cancer (27-34). Existing evidence, however, does not seem to support the involvement of LOI in ovarian cancer. One study evaluated 27 ovarian tumor samples, and of the 11 tumors which were informative, none showed biallelic expression of IGF-II (35), suggesting that LOI may not be responsible for increased IGF-II expression in ovarian cancer. Other studies reported that LOI was not common in epithelial ovarian cancer (36) and only 5 of 20 informative samples had LOI in IGF-II (37). A recent study also showed that LOI in IGF-II was not common in ovarian cancer (38). Thus, based on these reports, high IGF-II expression in ovarian cancer may be more relevant to the activation of IGF-II fetal promoters than loss of imprinting.

In summary, we analyzed IGF-II activity in ovarian cancer by examining promoter methylation, promoter specific expression, as well as overall expression at both mRNA and peptide levels. The results showed that the expression of IGF-II from three promoters located in a $\mathrm{CpG}$ island was affected by methylation. Methylation suppressed promoterspecific expression. Promoter 3 methylation and expression appeared to have a dominant role in ovarian cancer. The study also showed that a methylation pattern between promoters 2 and 3 was more relevant to the features of ovarian cancer than methylation determined by a single assay or based on individual promoter. The methylation pattern of IGF-II may have potential clinical implication in ovarian cancer disease management.

\section{Acknowledgements}

Dr Herbert Yu is supported by NIH grants CA098346 and AG21392. Dr Dionyssios Katsaros is supported in part by the Regione Riemonte Grant.

\section{References}

1. Jones JI and Clemmons DR: Insulin-like growth factors and their binding proteins: biological actions. Endocr Rev 16: 3-34, 1995.

2. Samani AA, Yakar S, LeRoith D and Brodt P: The role of the IGF system in cancer growth and metastasis: overview and recent insights. Endocr Rev 28: 20-47, 2007.

3. Randhawa $\mathrm{R}$ and Cohen P: The role of the insulin-like growth factor system in prenatal growth. Mol Genet Metab 86: 84-90, 2005.

4. Van Dijk MA, van Schaik FM, Bootsma HJ, Holthuizen P and Sussenbach JS: Initial characterization of the four promoters of the human insulin-like growth factor II gene. Mol Cell Endocrinol 81: 81-94, 1991.

5. Sussenbach JS, Rodenburg RJ, Scheper W and Holthuizen P: Transcriptional and post-transcriptional regulation of the human IGF-II gene expression. Adv Exp Med Biol 343: 63-71, 1993.

6. Gray A, Tam AW, Dull TJ, et al: Tissue-specific and developmentally regulated transcription of the insulin-like growth factor 2 gene. DNA 6: 283-295, 1987.

7. Wolffe AP and Matzke MA: Epigenetics: regulation through repression. Science 286: 481-486, 1999.

8. Chao W and D'Amore PA: IGF2: epigenetic regulation and role in development and disease. Cytokine Growth Factor Rev 19: 111-120, 2008.

9. Sawiris GP, Sherman-Baust CA, Becker KG, Cheadle C, Teichberg D and Morin PJ: Development of a highly specialized cDNA array for the study and diagnosis of epithelial ovarian cancer. Cancer Res 62: 2923-2928, 2002

10. Sayer RA, Lancaster JM, Pittman J, et al: High insulin-like growth factor-2 (IGF-2) gene expression is an independent predictor of poor survival for patients with advanced stage serous epithelial ovarian cancer. Gynecol Oncol 96: 355-361, 2005.

11. Lu L, Katsaros D, Wiley A, et al: The relationship of insulinlike growth factor-II, insulin-like growth factor binding protein-3, and estrogen receptor-alpha expression to disease progression in epithelial ovarian cancer. Clin Cancer Res 12: 1208-1214, 2006.

12. Lu L, Katsaros D, Wiley A, et al: Promoter-specific transcription of insulin-like growth factor-II in epithelial ovarian cancer. Gynecol Oncol 103: 990-995, 2006.

13. Jones PA and Baylin SB: The fundamental role of epigenetic events in cancer. Nat Rev Genet 3: 415-428, 2002.

14. Beeghly AC, Katsaros D, Wiley AL, et al: IGF-II promoter methylation and ovarian cancer prognosis. J Cancer Res Clin Oncol 133: 713-723, 2007.

15. Lu L, Katsaros D, Wiley A, Rigault de la Longrais IA, Puopolo M and Yu H: Expression of MDR 1 in epithelial ovarian cancer and its association with disease progression. Oncol Res 16: 395-403, 2007.

16. Holthuizen P, van Dijk MA, Rodenburg RJ, Koonen-Reemst AM and Sussenbach JS: Transcriptional regulation of the major promoters of the human IGF-II gene. Mol Reprod Dev 35: 391-393, 1993.

17. Li X, Nong Z, Ekstrom C, et al: Disrupted IGF2 promoter control by silencing of promoter P1 in human hepatocellular carcinoma. Cancer Res 57: 2048-2054, 1997.

18. Mineo R, Fichera E, Liang SJ and Fujita-Yamaguchi Y: Promoter usage for insulin-like growth factor-II in cancerous and benign human breast, prostate, and bladder tissues, and confirmation of a 10th exon. Biochem Biophys Res Commun 268: 886-892, 2000.

19. Hartmann W, Waha A, Koch A, et al: Promoter-specific transcription of the IGF2 gene: a novel rapid, non-radioactive and highly sensitive protocol for mRNA analysis. Virchows Arch 439: 803-807, 2001. 
20. Tang SH, Yang DH, Huang W, et al: Differential promoter usage for insulin-like growth factor-II gene in Chinese hepatocellular carcinoma with hepatitis B virus infection. Cancer Detect Prev 30: 192-203, 2006

21. Li X, Kogner P, Sandstedt B, Haas OA and Ekstrom TJ: Promoter-specific methylation and expression alterations of igf 2 and h19 are involved in human hepatoblastoma. Int J Cancer 75: 176-180, 1998.

22. Eriksson T, Frisk T, Gray SG, et al: Methylation changes in the human IGF2 $\mathrm{p} 3$ promoter parallel IGF2 expression in the primary tumor, established cell line, and xenograft of a human hepatoblastoma. Exp Cell Res 270: 88-95, 2001.

23. Su HY, Lai HC, Lin YW, Chou YC, Liu CY and Yu MH: An epigenetic marker panel for screening and prognostic prediction of ovarian cancer. Int J Cancer 124: 387-393, 2009.

24. Barton CA, Hacker NF, Clark SJ and O'Brien PM: DNA methylation changes in ovarian cancer: implications for early diagnosis, prognosis and treatment. Gynecol Oncol 109: 129-139, 2008

25. Kaneda A, Wang CJ, Cheong R, et al: Enhanced sensitivity to IGF-II signaling links loss of imprinting of IGF2 to increased cell proliferation and tumor risk. Proc Natl Acad Sci USA 104: 20926-20931, 2007.

26. Sakatani T, Kaneda A, Iacobuzio-Donahue CA, et al: Loss of imprinting of IGF2 alters intestinal maturation and tumorigenesis in mice. Science 307: 1976-1978, 2005.

27. Ogawa O, McNoe LA, Eccles MR, Morison IM and Reeve AE: Human insulin-like growth factor type I and type II receptors are not imprinted. Hum Mol Genet 2: 2163-2165, 1993.

28. Douc-Rasy S, Barrois M, Fogel S, et al: High incidence of loss of heterozygosity and abnormal imprinting of H19 and IGF2 genes in invasive cervical carcinomas. Uncoupling of H19 and IGF2 expression and biallelic hypomethylation of H19. Oncogene 12: 423-430, 1996
29. Wu MS, Wang HP, Lin CC, et al: Loss of imprinting and overexpression of IGF2 gene in gastric adenocarcinoma. Cancer Lett 120: 9-14, 1997.

30. Nonomura N, Nishimura K, Miki T, et al: Loss of imprinting of the insulin-like growth factor II gene in renal cell carcinoma. Cancer Res 57: 2575-2577, 1997.

31. El-Naggar AK, Lai S, Tucker SA, et al: Frequent loss of imprinting at the IGF2 and H19 genes in head and neck squamous carcinoma. Oncogene 18: 7063-7069, 1999.

32. Kohda M, Hoshiya H, Katoh M, et al: Frequent loss of imprinting of IGF2 and MEST in lung adenocarcinoma. Mol Carcinog 31: 184-191, 2001.

33. Cui H, Onyango P, Brandenburg S, Wu Y, Hsieh CL and Feinberg AP: Loss of imprinting in colorectal cancer linked to hypomethylation of H19 and IGF2. Cancer Res 62: 6442-6446, 2002.

34. Cui H: Loss of imprinting of IGF2 as an epigenetic marker for the risk of human cancer. Dis Markers 23: 105-112, 2007.

35. Yun K, Fukumoto M and Jinno Y: Monoallelic expression of the insulin-like growth factor-2 gene in ovarian cancer. Am J Pathol 148: 1081-1087, 1996.

36. Kim HT, Choi BH, Niikawa N, Lee TS and Chang SI: Frequent loss of imprinting of the H19 and IGF-II genes in ovarian tumors. Am J Med Genet 80: 391-395, 1998.

37. Chen CL, Ip SM, Cheng D, Wong LC and Ngan HY: Loss of imprinting of the IGF-II and H19 genes in epithelial ovarian cancer. Clin Cancer Res 6: 474-479, 2000.

38. Murphy SK, Huang Z, Wen Y, et al: Frequent IGF2/H19 domain epigenetic alterations and elevated IGF2 expression in epithelial ovarian cancer. Mol Cancer Res 4: 283-292, 2006. 